\title{
Characteristic induction of steroidogenic factor 1 (SF-1) and DAX-1 and enhanced expression of glucocorticoid synthesis-related genes in adrenals from spontaneously hypertensive rats
}

\author{
Naoki Harikai \\ School of Pharmacy and Pharmaceutical Sciences, Mukogawa Women's University, Nishinomiya, Hyogo, Japan
}

\begin{abstract}
To gain insight into the molecular mechanism of hyper-glucocorticoidism in spontaneously hypertensive rats (SHR), this study investigated the expression of genes related to glucocorticoid synthesis, melanocortin 2 receptor (MC2R), steroidogenic acute regulatory protein (StAR), cytochrome $\mathrm{P} 450$ side chain cleavage enzyme (P450scc) and $11 \beta$-hydroxylase (P450c11), and the transcription factors of steroidogenic factor 1 (SF-1), which stimulates expression of the above gene, and DAX-1 (dosage-sensitive sex reversal-adrenal hypoplasia congenita critical region on the $\mathrm{X}$ chromosome gene 1), which negatively regulates the transcriptional activity of SF-1, in adrenals from SHR. On quantitative real time RT-PCR analysis, gene expression levels of MC2R, StAR, P450scc and P450c11 in SHR were high compared with those in normotensive Wistar Kyoto rats (WKY). The gene expression level of SF-1 was not different between the two rats. However, the expression level of DAX-1 in SHR was markedly lower than that in WKY. Furthermore, the protein levels of StAR, SF-1 and DAX-1 determined by Western blot analysis coincided well with the gene expressions in both rats. These results suggest that the low level of DAX-1 may enhance the transcriptional activity of SF-1 and expression of genes related to glucocorticoid synthesis, which are targeted by SF-1, in adrenals from SHR.
\end{abstract}

Key words: Cytochrome P450 side chain cleavage enzyme - 11 $\beta$-Hydroxylase - Melanocortin 2 receptor - Steroidogenic acute regulatory protein — Steroid synthesis

\begin{abstract}
Abbreviations: DAX-1, dosage-sensitive sex reversal-adrenal hypoplasia congenita critical region on the X chromosome gene 1; MC2R, melanocortin 2 receptor; P450scc, cytochrome P450 side chain cleavage enzyme; P450c11, 11 $\beta$-hydroxylase; SF-1, steroidogenic factor 1; SHR, spontaneously hypertensive rats; StAR, steroidogenic acute regulatory protein; WKY, Wistar kyoto rats.
\end{abstract}

\section{Introduction}

Spontaneously hypertensive rats (SHR) have been widely used for physiological and pharmacological studies on hypertension. Removal of the adrenal gland from SHR results in a fall of blood pressure, indicating the involvement of adrenal hormones on the development of hypertension in SHR (Aoki 1963; Ruch et al. 1984; Hashimoto et al. 1989). Glucocorticoid is one of the adrenal hormones

Correspondence to: Naoki Harikai, School of Pharmacy and Pharmaceutical Sciences, Mukogawa Women's University, 11-68 Koshien Kyuban-cho, Nishinomiya, Hyogo 663-8179, Japan E-mail: harikai@mukogawa-u.ac.jp and may be a factor in hypertension development, since glucocorticoid supplementation restored hypertension in adrenalectomized SHR (Hashimoto et al. 1989). Furthermore, SHR had high blood glucocorticoid levels under basal condition as compared to normotensive Wistar Kyoto rats (WKY) (Hashimoto et al. 1989; Djordjevic et al. 2007). Hyperglucocorticoidism may have important implications for the pathological development in SHR, but the molecular mechanism of this hyperglucocorticoidism is not clear.

Glucocorticoid synthesis involves the participation of various factors, such as melanocortin 2 receptor (MC2R), steroidogenic acute regulatory protein (StAR), cytochrome P450 side chain cleavage enzyme (P450scc) and 11 $\beta$-hydroxylase (P450c11) (where MC2R is an ACTH receptor, 
StAR delivers cholesterol to the mitochondria, P450scc catalyzes transformation of cholesterol to pregnenolone, and P450c11 converts 11-deoxycorticosterone to corticosterone, the principal glucocorticoid in rodents). Transformation of cholesterol to pregnenolone was long believed to be the ratelimiting step in steroidogenesis. This limiting step was not due to P450scc activity but, rather, to StAR activity (Kallen et al. 1998).

These gene expressions involved in glucocorticoid synthesis are mainly regulated by steroidogenic factor 1 (SF-1). Indeed, there are SF-1 binding sites in the promoter region of MC2R, StAR, P450scc and P450c11 genes (Rice et al. 1990; Cammas et al. 1997; Caron et al. 1997a; Wang et al. 2000). On the other hand, DAX-1, named for dosage-sensitive sex reversal-adrenal hypoplasia congenita critical region on the $\mathrm{X}$ chromosome gene 1, is coexpressed with SF-1 and known to inhibit the expression of the above-mentioned SF-1 target genes (Zazopoulos et al. 1997; Lalli et al. 1998; Zwermann et al. 2005). The inhibitory action of DAX-1 was explained as involving its direct binding to SF-1 (Ito et al. 1997) or the hairpin structure in the promoter region of SF-1 target genes (Zazopoulos et al. 1997).

In humans, mutations of SF-1 or DAX-1 genes were reported to impair adrenal steroid synthesis function (Muscatelli et al. 1994; Achermann et al. 1999). Disruptions of either genes in mice produced disturbances in the development and function of the adrenal and gonadal glands (Luo et al. 1994; Yu et al. 1998). SF-1 (+/-) mice, loaded with stress by prolonged fasting, were observed to display both greater increase of ACTH levels and smaller increase of corticosterone levels in plasma (Bland et al. 2000). On the other hand, DAX-1 (-/Y) mice exhibited high MC2R expression in the adrenals, and the mice loaded with restraint-induced stress showed large increases of glucocorticoid levels despite a small increase of ACTH levels in plasma (Babu et al. 2002). These observations indicate that the decrease of SF-1 suppresses glucocorticoid synthesis while a decrease of DAX-1 enhances it.

To elucidate the molecular mechanism involved in hyperglucocorticoidism in SHR, we focused on the glucocorticoid synthesis-related genes regulated by SF-1 and the balance between SF-1 and DAX-1 levels in the adrenals. In this study, we examined the expression levels of glucocorticoid synthesis-related genes, MC2R, StAR, P450scc and P450c11, and these transcription factor genes, SF-1 and DAX-1, and the protein levels of StAR, involved in the rate-limiting step in steroidogenesis, SF-1 and DAX-1 in SHR in comparison to those in normotensive WKY.

\section{Materials and Methods}

\section{Animals}

Male WKY and SHR were purchased from SLC Inc. (Shizuoka, Japan). Animals were housed in cages at $23 \pm 1^{\circ} \mathrm{C}$ and $55 \pm 5 \%$ relative humidity. The light-dark cycle was kept unchanged throughout the experiment with lights on from 08:00 to 20:00 h daily. Animals at 8 weeks of age were weighed, and their blood pressure was measured by tail cuff methods using MK-2000 (Muromachi Kikai Co., Tokyo, Japan). Serum corticosterone levels were measured by high performance liquid chromatography (Shimizu et al. 1983). All animal experiments were approved by the Mukogawa Women's University Animal Welfare Committee.

\section{Real time RT-PCR}

Total RNA was extracted from rat adrenals using the Sepasol RNA I super (Nacalai tesque, Kyoto, Japan). The concentration of extracted RNA was determined by absorbance readings at $260 \mathrm{~nm}$ with a SmartSpec Plus spectrophotometer (Bio-Rad, CA, USA). One microgram of total RNA from each sample was reverse transcribed to cDNA using the Reverse Transcription Reagent and oligo dT primers (both from (Takara, Shiga, Japan)). In a final volume of $20 \mu \mathrm{l}, 2.5 \mathrm{ng}$ of cDNA was mixed with the SYBR Premix Ex Taq reagents (Takara), the ROX Reference Dye (Takara) to calibrate the fluorescence detection and primers. The primer pairs were selected to yield a single PCR product based on dissociation curves. The PCR product sizes estimated on gel electrophoresis were as predicted (Fig. 1). The primer sequences are shown in Table 1. Real time RT-PCR was performed using

Table 1. Nucleotide sequences of the PCR primers used

\begin{tabular}{lll}
\hline Gene & \multicolumn{1}{c}{ Forward } & \multicolumn{1}{c}{ Reverse } \\
\hline$\beta$-actin & 5'-TTCCTGGGTATGGAATCCTG-3' & 5'-CAGGAGGAGCAATGATCTTG-3' \\
MC2R & 5'-TGAAGGGTGCCATGACATTG-3' & 5'-TCAACATGCCATTGACCTGG-3' \\
StAR & 5'-CATCAGAGCTGAACACGGTC-3' & 5'-CCACCCCTTGAGGTCAATAC-3' \\
P450scc & 5'-TCCAGCCAAGACTTTGGTGC-3' & 5'-CCAGCACGTTGATGAGGAAG-3' \\
P450c11 & 5'-CTTGAGGCTCTACCCTGTTG-3' & 5'-GACGAATGTCCCAGCAGGGA-3' \\
SF-1 & 5'-AGAGCTGCAAGGGCTTCTTC-3' & 5'-ATCAGCACGCACAGCTTC-3' \\
DAX-1 & 5'-TTTAACCCAGACCTGCCTGG-3' & 5'-TGCTGACGGCACCAATGATG-3' \\
\hline
\end{tabular}




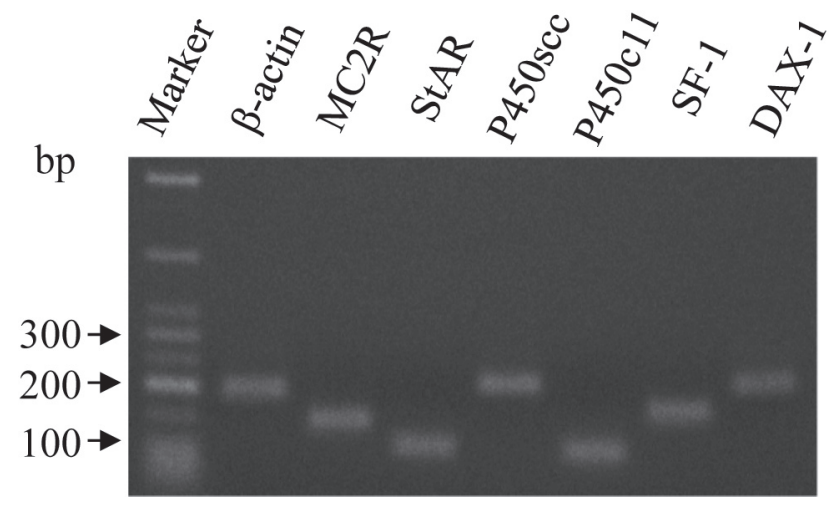

Figure 1. Agarose (2\%) gel electrophoresis of real-time PCR products. The predicted sizes of PCR products were as follows: $\beta$-actin - 205 bp; MC2R - 150 bp; StAR - 106 bp; P450scc - 215 bp; P450c11 - 92 bp; SF-1 - 167 bp; and DAX-1 - 214 bp.

a 7000 Real-Time PCR System (Applied Biosystems, CA, USA). The thermal cycle programs were as follows: $10 \mathrm{~s}$ at $95^{\circ} \mathrm{C}$ followed by amplification of the cDNA for 40 cycles with $5 \mathrm{~s}$ at $95^{\circ} \mathrm{C}$ and $32 \mathrm{~s}$ at $62^{\circ} \mathrm{C}$ for all primers. A standard curve was run on each plate to validate the method and to determinate the efficiency of the reaction, which was taken into account in the calculations. The cDNA for the standard curve was prepared from the mixture of RNA extracted from adrenals in WKY. The concentration of this RNA was determined by a SmartSpec Plus spectrophotometer. The standard curve for each gene showed linearity. All samples were run in duplicate and the values were normalized to the values of $\beta$-actin.

\section{Western blotting}

Adrenals from each rat was homogenized in lysis buffer (pH 7.4), consisting of $50 \mathrm{mM}$ Tris, $150 \mathrm{mM} \mathrm{NaCl}, 1 \mathrm{mM}$ EDTA, 1\% Triton-X and protease inhibitors cocktail (Nacalai Tesque). The protein concentration of the sample was determined by BCA protein assay reagents (Piece, IL, USA). Each sample was diluted to a protein concentration of $2 \mu \mathrm{g} / \mu \mathrm{l}$ in lysis buffer. After addition of an equivalent volume of SDS-PAGE loading buffer ( $\mathrm{pH}$ 6.8), consisting of $0.1 \mathrm{M}$ Tris, 2\% SDS, 12\% 2-mercaptoethanol, 20\% glycerol and $0.01 \%$ bromphenol blue, the sample was denatured at $100^{\circ} \mathrm{C}$ for $5 \mathrm{~min}$. Next, $15 \mu \mathrm{l}$ of the sample was separated by $10 \%$ SDS-PAGE and transferred to polyvinylidendifluoride membrane using Trans-Blot semi-dry electrophoretic transfer cell (Bio-Rad Laboratories, CA, USA). The membrane was incubated in Blocking One (Nacalai Tesque) for $3 \mathrm{~h}$ at $4^{\circ} \mathrm{C}$, and in primary antibodies to $ß$-actin $(1: 4000$, Sigma, MO, USA), StAR ( $1: 2000$, Affinity BioReagents), SF-1 (1 : 1000, Affinity BioReagents,
CO, USA) or DAX-1 (1 : 500, Santa Cruz Biotechnology, CA, USA) overnight at $4^{\circ} \mathrm{C}$. The washed membrane was then incubated with suitable secondary IgG conjugated to horseradish peroxidase (DakoCytomation, Glostrup, Denmark). Antibody binding to the membrane was visualized using ECL Western blotting detection reagents (Amersham Biosciences, NJ, USA). A range of exposure times for each immunoblot assured that signal intensity was proportional to protein concentration. Sion Image (Scion Corporation, MD, USA) was used to quantify the blots and the values were normalized to the values of $\beta$-actin.

\section{Statistical analysis}

Data are generally presented as mean \pm standard deviation of 4 rats per group. Because it was possible that serum corticosterone levels were influenced by simple handling and experimental procedures, such as moving cage (Gärtner et al. 1980), the levels were measured for 10 rats per group to obtain valid results. Differences in the data between groups were analyzed by Student's $t$-test. Statistical significance was considered at $p<0.05$. Analyses were performed using Excel 2000 (Microsoft, WA, USA).

\section{Results}

\section{Physiological parameters and serum corticosterone levels}

Body weight did not differ between SHR and WKY (WKY at $235.5 \pm 4.4 \mathrm{~g} v s$. SHR at $234.5 \pm 7.0 \mathrm{~g}, p=0.82$ ) (Table 2). However, the adrenal weight in SHR was significantly smaller than that in WKY (WKY at $31.0 \pm 1.5 \mathrm{mg} v s$. SHR at 24.6 $\pm 0.8 \mathrm{mg}, p<0.05$ ). Blood pressure in SHR was significantly higher than that in WKY (WKY at $98.0 \pm 6.9 \mathrm{mmHg} v$. SHR at $177.1 \pm 10.1 \mathrm{mmHg}, p<0.05)$. The serum corticosterone level in SHR was higher than that in WKY under basal condition (WKY at $53.4 \pm 43.9 \mathrm{ng} / \mathrm{ml} v$ s. SHR at 125.1 $\pm 87.2 \mathrm{ng} / \mathrm{ml}, p<0.05)$.

Table 2. Physiological parameters and serum corticosterone levels in WKY and SHR

\begin{tabular}{lcc}
\hline & WKY & SHR \\
\hline Body weight $(\mathrm{g})$ & $233.5 \pm 4.4$ & $234.5 \pm 7.0$ \\
Adrenal weight $(\mathrm{mg})$ & $31.0 \pm 1.5$ & $24.6 \pm 0.8^{\star}$ \\
Blood pressure $(\mathrm{mmHg})$ & $98.0 \pm 6.9$ & $177.1 \pm 10.1^{\star}$ \\
Serum corticosterone $(\mathrm{ng} / \mathrm{ml})$ & $53.4 \pm 43.9$ & $125.1 \pm 87.2^{\star}$ \\
\hline
\end{tabular}

WKY, Wistar Kyoto rats; SHR, spontaneously hypertensive rats. Values are mean $\pm \operatorname{SD}(n=4-10) ;{ }^{*} p<0.05$. 


\section{MC2R, StAR, P450scc and P450c11 in adrenals}

MC2R, StAR, P450scc and P450c11 mRNA levels in SHR were 1.7-fold, 1.9-fold, 1.4-fold and 2.6-fold higher than those in WKY, respectively $(p<0.05)$ (Fig. 2$)$. In Western blot analysis, the immunoreactive band of StAR was detected at $30 \mathrm{kDa}$ (Fig. 4). StAR protein level in SHR was 1.5 -fold higher than that in WKY $(p<0.05)$.

\section{SF-1 and DAX-1 in adrenals}

SF-1 mRNA level did not differ in the adrenals of between SHR and WKY ( $p=0.91)$ (Fig. 3). On the other hand, DAX-1 mRNA level in SHR was 2.4-fold lower than that in WKY $(p<0.05)$. In Western blot analysis, immunoreactive bands of SF- 1 and DAX-1 were at $53 \mathrm{kDa}$ and $52 \mathrm{kDa}$, respectively (Fig. 4). The SF-1 protein level did not differ in the adrenals of between SHR and WKY $(p=0.64)$. On the other hand, the DAX-1 protein level in SHR was 1.3-fold lower than that in WKY $(p<0.05)$. Accordingly, DAX-1 in adrenals from SHR was decreased in both mRNA and protein levels.

\section{Discussion}

The weights of adrenals in SHR were reported to consistently increase during the period of rapidly escalating blood pressure (Iams et al. 1979). However, the value in SHR at 8 weeks, which have early onset of hypertension, was found to be smaller than that in WKY, and furthermore, the value

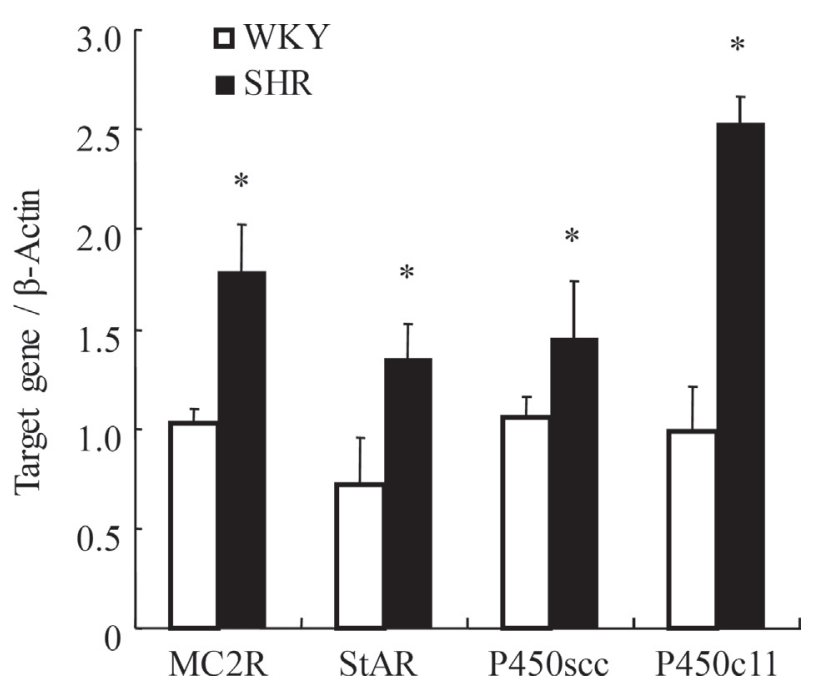

Figure 2. Real time RT-PCR analysis of MC2R, StAR, P450scc and P450c11 in adrenals from WKY and SHR. Differences of MC2R, StAR, P450scc and P450c11 mRNA expressions in adrenals between WKY and SHR $\left({ }^{*} p<0.05\right)$. Values are mean $\pm \operatorname{SD}(n=4)$. in SHR after 12 weeks whose blood pressure was elevated to $230-250 \mathrm{mmHg}$ was almost the same as that in WKY (Fukuda et al. 2004), indicating that hypertension in SHR is genetically programmed irrespective of adrenal hypertrophy. In this study, we found that the weight of the adrenals in SHR was lower than that in WKY, although the body weight was almost the same, and the blood pressure in SHR was higher than that in WKY (Table 2). These findings led us to assume that SHR at 8 weeks could be a convenient model rat for analyses of the characteristic alterations in gene expressions related to glucocorticoid synthesis in the adrenals at the early onset of hypertension. SHR at 8 weeks under basal conditions had a higher blood corticosterone level than WKY (Table 2), as previously reported for SHR at 15 weeks (Djordjevic et al. 2007).

The expressions of genes related to glucocorticoid synthesis, MC2R, StAR, P450scc and P450c11, were investigated in the adrenals from SHR accompanied by hyperglucocorticoidism. These expression levels in SHR were higher than those from WKY, respectively (Fig. 2). In a recent report, the gene expression profiles in adrenals from SHR were examined using DNA microarrays, and the data were compared with those from WKY (Ashenagar et al. 2010). However, we did not find this in our study. The reasons might be that the reported study focused on genes with more than 4 -fold or less than $1 / 4$-fold expression changes, and covered a fewer number of comparisons. According to another report using a semi-quantitative method, gene expression of P450c11 in adrenals from SHR was not different from that in WKY while gene expression

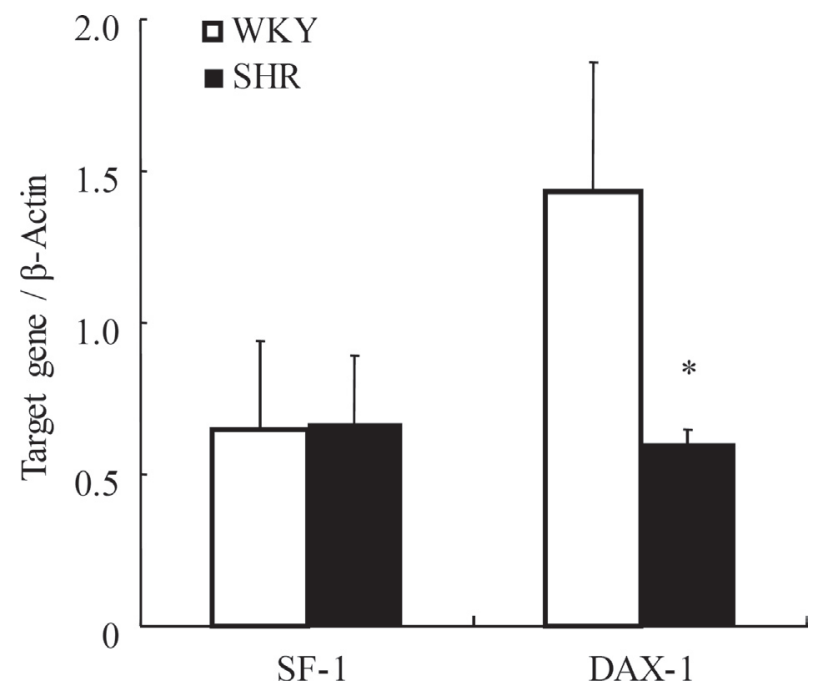

Figure 3. Real time RT-PCR analysis of SF- 1 and DAX-1 in adrenals from WKY and SHR. Differences of SF-1 and DAX-1 mRNA expressions in adrenals between WKY and SHR $\left({ }^{*} \mathrm{p}<0.05\right)$. Values are mean $\pm \mathrm{SD}(n=4)$. 
A

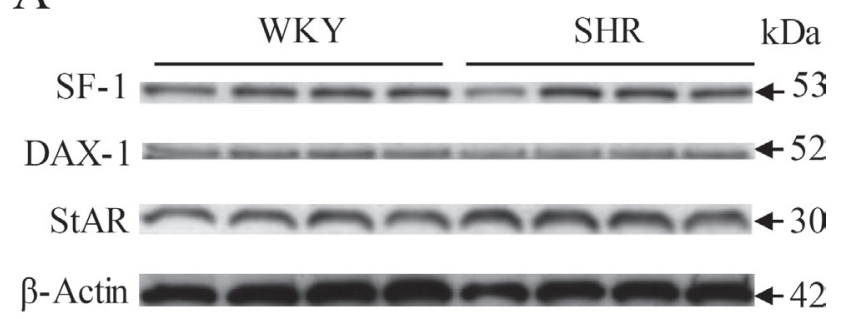

B

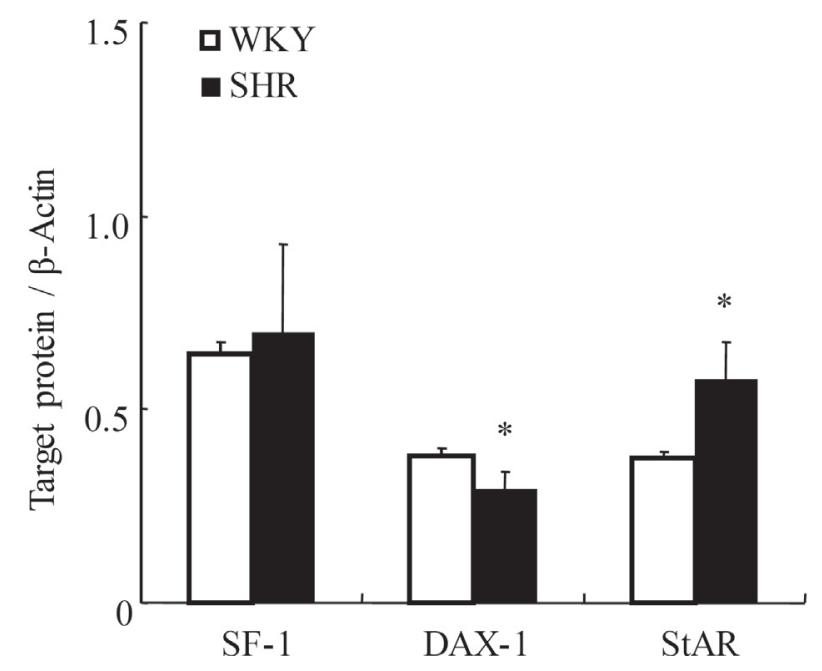

Figure 4. Western blot analysis of SF-1, DAX-1 and StAR in adrenals from WKY and SHR. A. Immunoreactive bands of SF-1, DAX-1, StAR and $\beta$-actin. B. Differences of SF-1, DAX- 1 and StAR protein levels in adrenals between WKY and SHR $\left({ }^{\star} p<0.05\right)$. Values are mean $\pm \operatorname{SD}(n=4)$.

of aldosterone synthase (P450aldo) was lower (Okamoto et al. 1995). Our results using quantitative PCR showed that gene expression of P450c11 in SHR was higher than that of WKY while gene expression of P450aldo did not differ (data not shown) in WKY. MC2R, StAR, P450scc and $\mathrm{P} 450 \mathrm{c} 11$ genes, indicating high expression levels in SHR in this study, are known to contain SF-1 binding sites in the promoter region and to be regulated by SF-1 (Rice et al. 1990; Cammas et al. 1997; Caron et al. 1997a; Wang et al. 2000). On the other hand, gene expression of P450aldo was decreased by overexpression of SF-1 in adrenocortical cells (Ye et al. 2009). These findings suggest that the transcriptional activity of SF-1 may be enhanced in the adrenals from SHR.

Subsequently, high expression of the glucocorticoid synthesis-related gene was then confirmed at the protein level. In steroid hormone synthesis, StAR regulated the rate-limiting step by controlling the delivery of choles- terol from the outer membrane to the inner membrane of mitochondria, where cholesterol was further converted to pregnenolone by P450scc (Stocco et al. 2005). In fact, mice lacking StAR and P450scc show severe defects in adrenal steroidogenesis (Caron et al. 1997b; Hu et al. 2002). Consequently, our present study compared the StAR protein level in adrenals between SHR and WKY. The high mRNA level of StAR in SHR was reflected in the protein level (Fig. 4). Accordingly, not only mRNA but also protein levels of factors involving adrenal glucocorticoid synthesis are characteristic of SHR.

The glucocorticoid synthesis-related genes shown in Fig. 2 were upregulated by SF-1. On the other hand, DAX-1 inhibited the expressions of these SF-1 target genes (Zazopoulos et al. 1997; Lalli et al. 1998; Zwermann et al. 2005). Our present study focused on these two transcription factors, and the mRNA and protein levels in adrenals were compared between SHR and WKY. The mRNA and protein levels of SF-1 did not differ (Figs. 3 and 4), but the mRNA and protein levels of DAX-1 in SHR were significantly lower than those in WKY. Cases of DAX-1 decrease or deficiency in the adrenal cells have already been reported. Screening a number of adrenocortical tumors, showed that gene expressions between DAX-1 and MC2R were negatively correlated (Zwermann et al. 2005). DAX-1 (-/Y) mice under stress condition produced high glucocorticoid levels in spite of low ACTH levels in the blood, and, furthermore, increased MC2R levels in the adrenals (Babu et al. 2002). By comparison, the same pattern, a high glucocorticoid level in spite of a low ACTH level, was also observed in SHR (Hashimoto et al. 1989). These findings suggested that the decrease of DAX-1 might be related to the high expression levels of adrenal glucocorticoid synthesis genes targeted by SF-1 and hyperglucocorticoidism in SHR. Further work is needed to clarify the molecular mechanism of hyperglucocorticoidism in SHR. On the other hand, ACTH stimulation has been reported to induce changes in the SF-1/DAX-1 protein ratio to fine tune ACTH responsiveness in adrenocortical cells (Ragazzon et al. 2006). Accordingly, not only the genetic but also the hormonal influences should be considered in trying to elucidate the mechanism of DAX-1 decrease in SHR.

In conclusion, this study found that expression levels of glucocorticoid synthesis-related genes, MC2R, StAR, P450scc and P450c11, were high in the adrenals from SHR in comparison with WKY. In studying the transcription factor for these genes, the expressions of SF-1 involved in positive regulation did not differ between SHR and WKY, but those of DAX-1 involved in negative regulation were significantly lower in SHR than those in WKY. These findings suggested that decrease of DAX-1 enhanced SF-1 transcriptional activity and then enhanced the expressions of glucocorticoid synthesis genes targeted by SF-1 in SHR. To clarify the molecular 
mechanism of the hyperglucocorticoidism in SHR, further study is needed based on this new perspective, focusing on the SF-1/DAX-1 balance.

Acknowledgments. The author thanks Dr. Atsushi Ichikawa and Dr. Yuzo Yoshida for their helpful discussions. This work was supported by MEXT HAITEKU (Japan), and Mukogawa Women's University.

\section{References}

Achermann J. C., Ito M., Ito M., Hindmarsh P. C., Jameson J. L. (1999): A mutation in the gene encoding steroidogenic factor1 causes XY sex reversal and adrenal failure in humans. Nat. Genet. 22, 125-126 http://dx.doi.org/10.1038/9629

Aoki K. (1963): Experimental studies on the relationship between endocrine organs and hypertension in spontaneously hypertensive rats. I. Effects of hypophysectomy, adrenalectomy, thyroidectomy, nephrectomy and sympathectomy on blood pressure. Jpn. Heart J. 186, 443-461 http://dx.doi.org/10.1536/ihj.4.443

Ashenagar M. S., Tabuchi M., Kinoshita K., Ooshima K., Niwa A., Watanabe Y., Yoshida M., Shimada K., Yasunaga T., Yamanishi H., Higashino H. (2010): Gene expression in the adrenal glands of three spontaneously hypertensive rat substrains. Mol. Med. Report. 3, 213-222

Babu P. S., Bavers D. L., Beuschlein F., Shah S., Jeffs B., Jameson J. L., Hammer G. D. (2002): Interaction between Dax-1 and steroidogenic factor-1 in vivo: increased adrenal responsiveness to ACTH in the absence of Dax-1. Endocrinology 143, $665-673$ http://dx.doi.org/10.1210/en.143.2.665

Bland M. L., Jamieson C. A., Akana S. F., Bornstein S. R., Eisenhofer G., Dallman M. F., Ingraham H. A. (2000): Haploinsufficiency of steroidogenic factor-1 in mice disrupts adrenal development leading to an impaired stress response. Proc. Natl. Acad. Sci. U. S. A. 97, 14488-14493 http://dx.doi.org/10.1073/pnas.97.26.14488

Cammas F. M., Pullinger G. D., Barker S., Clark A. J. (1997): The mouse adrenocorticotropin receptor gene: cloning and characterization of its promoter and evidence for a role for the orphan nuclear receptor steroidogenic factor 1. Mol. Endocrinol. 11, 867-876 http://dx.doi.org/10.1210/me.11.7.867

Caron K. M., Ikeda Y., Soo S. C., Stocco D. M., Parker K. L., Clark B. J. (1997a): Characterization of the promoter region of the mouse gene encoding the steroidogenic acute regulatory protein. Mol. Endocrinol. 11, 138-147 http://dx.doi.org/10.1210/me.11.2.138

Caron K. M., Soo S. C., Wetsel W. C., Stocco D. M., Clark B. J., Parker K. L. (1997b): Targeted disruption of the mouse gene encoding steroidogenic acute regulatory protein provides insights into congenital lipoid adrenal hyperplasia. Proc. Natl. Acad. Sci. U. S. A. 94, 11540-11545 http://dx.doi.org/10.1073/pnas.94.21.11540
Djordjevic J., Vuckovic T., Jasnic N., Cvijic G. (2007): Effect of various stressors on the blood ACTH and corticosterone concentration in normotensive Wistar and spontaneously hypertensive Wistar-Kyoto rats. Gen. Comp. Endocrinol. 153, 217-220 http://dx.doi.org/10.1016/j.ygcen.2007.02.004

Fukuda S., Tsuchikura S., Iida H. (2004): Age-related changes in blood pressure, hematological values, concentrations of serum biochemical constituents and weights of organs in the SHR/Izm, SHRSP/Izm and WKY/Izm. Exp. Anim. 53, 67-72 http://dx.doi.org/10.1538/expanim.53.67

Gärtner K., Büttner D., Döhler K., Friedel R., Lindena J., Trautschold I. (1980): Stress response of rats to handling and experimental procedures. Lab. Anim. 14, 267-274 http://dx.doi.org/10.1258/002367780780937454

Hashimoto K., Makino S., Hirasawa R. Takao T., Sugawara M., Murakami K., Ono K., Ota Z. (1989): Abnormalities in the hypothalamo-pituitary-adrenal axis in spontaneously hypertensive rats during development of hypertension. Endocrinology $125,1161-1167$ http://dx.doi.org/10.1210/endo-125-3-1161

Hu M. C., Hsu N. C., El Hadj N. B., Pai C. I., Chu H. P., Wang C. K., Chung B. C. (2002): Steroid deficiency syndromes in mice with targeted disruption of Cyp11a1. Mol. Endocrinol. 16, 1943-1950 http://dx.doi.org/10.1210/me.2002-0055

Iams S. G., McMurthy J. P., Wexler B. C. (1979): Aldosterone, deoxycorticosterone, corticosterone, and prolactin changes during the lifespan of chronically and spontaneously hypertensive rats. Endocrinology 104, 1357-1363 http://dx.doi.org/10.1210/endo-104-5-1357

Ito M., Yu R., Jameson J. L. (1997): DAX-1 inhibits SF-1-mediated transactivation via a carboxy-terminal domain that is deleted in adrenal hypoplasia congenita. Mol. Cell Biol. 17, 1476-1483

Kallen C. B., Arakane F., Christenson L. K., Watari H., Devoto L., Strauss J. F. 3rd (1998): Unveiling the mechanism of action and regulation of the steroidogenic acute regulatory protein. Mol. Cell Endocrinol. 145, 39-45 http://dx.doi.org/10.1016/S0303-7207(98)00167-1

Lalli E., Melner M. H., Stocco D. M., Sassone-Corsi P. (1998): DAX1 blocks steroid production at multiple levels. Endocrinology 139, 4237-4243 http://dx.doi.org/10.1210/en.139.10.4237

Luo X., Ikeda Y., Parker K. L. (1994): A cell-specific nuclear receptor is essential for adrenal and gonadal development and sexual differentiation. Cell 77, 481-490 http://dx.doi.org/10.1016/0092-8674(94)90211-9

Muscatelli F., Strom T. M., Walker A. P., Zanaria E., Recan D., Meindl A., Bardoni B., Guioli S., Zehetner G., Rabl W., Schwarz H. P., Kaplan J. C., Camerino G., Meitinger T., Monaco A. P. (1994): Mutations in the DAX-1 gene give rise to both X-linked adrenal hypoplasia congenita and hypogonadotropic hypogonadism. Nature 372, 672-676 http://dx.doi.org/10.1038/372672a0

Okamoto M., Nonaka Y., Ohta M., Takemori H., Halder S. K., Wang Z. N., Sun T., Hatano O., Takakusu A., Murakami T. (1995): 
Cytochrome P450(11 beta): structure-function relationship of the enzyme and its involvement in blood pressure regulation. J. Steroid Biochem. Mol. Biol. 53, 89-94 http://dx.doi.org/10.1016/0960-0760(95)00025-U

Ragazzon B., Lefrançois-Martinez A. M., Val P., Sahut-Barnola I. Tournaire C., Chambon C., Gachancard-Bouya J. L., Begue R. J., Veyssière G., Martinez A. (2006): Adrenocorticotropin-dependent changes in SF-1/DAX-1 ratio influence steroidogenic genes expression in a novel model of glucocorticoid-producing adrenocortical cell lines derived from targeted tumorigenesis. Endocrinology 147, 1805-1818 http://dx.doi.org/10.1210/en.2005-1279

Rice D. A., Kirkman M. S., Aitken L. D., Mouw A. R., Schimmer B. P., Parker K. L. (1990): Analysis of the promoter region of the gene encoding mouse cholesterol side-chain cleavage enzyme. J. Biol. Chem. 265, 11713-11720

Ruch W., Baumann J. B., Hausler A., Otten U. H., Siegl H., Girard J. (1984): Importance of the adrenal cortex for development and maintenance of hypertension in spontaneously hypertensive rats. Acta Endocrinol. 105, 417-424

Shimizu K., Amagaya S., Ogihara Y. (1983): Analysis of corticosterone in the serum of mice and rats using high-performance liquid chromatography. J. Chromatogr. 272, 170-175

Stocco D. M., Wang X., Jo Y., Manna P. R. (2005): Multiple signaling pathways regulating steroidogenesis and steroidogenic acute regulatory protein expression: more complicated than we thought. Mol. Endocrinol. 19, 2647-2659 http://dx.doi.org/10.1210/me.2004-0532
Wang X. L., Bassett M., Zhang Y., Yin S., Clyne C., White P. C., Rainey W. E. (2000): Transcriptional regulation of human 11beta-hydroxylase (hCYP11B1). Endocrinology 141, 3587-3594

http://dx.doi.org/10.1210/en.141.10.3587

Ye P., Nakamura Y., Lalli E., Rainey W. E. (2009): Differential effects of high and low steroidogenic factor-1 expression on CYP11B2 expression and aldosterone production in adrenocortical cells. Endocrinology 150, 1303-1309 http://dx.doi.org/10.1210/en.2008-0667

Yu R. N., Ito M., Saunders T. L., Camper S. A., Jameson J. L. (1998): Role of Ahch in gonadal development and gametogenesis. Nat. Genet. 20, 353-357 http://dx.doi.org/10.1038/3822

Zazopoulos E., Lalli E., Stocco D. M., Sassone-Corsi P. (1997): DNA binding and transcriptional repression by DAX-1 blocks steroidogenesis. Nature 390, 311-315 http://dx.doi.org/10.1038/36899

Zwermann O., Beuschlein F., Lalli E., Klink A., Sassone-Corsi P., Reincke M. (2005): Clinical and molecular evidence for DAX-1 inhibition of steroidogenic factor-1-dependent ACTH receptor gene expression. Eur. J. Endocrinol. 152, 769-776 http://dx.doi.org/10.1530/eje.1.01908

Received: July 13, 2011

Final version accepted: September 14, 2011 